\title{
Interaction Design of Safety Tourism Apps
}

\author{
Andhika Giri Persada, Muhammad Anshari \\ \{andhika.giri@uii.ac.id, muhammad.anshari@gmail.com\} \\ Teknik Informatika, Universitas Islam Indonesia, Jalan Kaliurang KM 14.5, Umbulmartani, \\ Ngemplak, Sleman, Yogyakarta, Indonesia ${ }^{1}$
}

\begin{abstract}
Travel through tourism places is kind of fun activity. However, criminal and safety issues cannot be predicted when and how it is occured. Application (apps) for tourism are spreading out today. Security and safety are becoming factors that preclude to traveling. Both Security and Safety are mentioned as only Safety in this paper. This problem must be addressed, and tourism apps is playing a key-role. In this study, we develop interaction design ( $\mathrm{IxD}$ ) of tourism apps which is accommodating preventive and first-aid. Preventive action by providing safety issues in each tourism place, while first-aid provides early assistance when occuring criminal incident. IxD is designed based on user experience approach. Ten's Nielsen principles are used as guideline, while cognitive walkthrough is used as measurement method. Lombok Island is chosen as case study. It has many potential tourism destination, which are growing rapidly. They have known for their social, natural and cultural tourism. Within this apps, we can inspect criminal vulnerability in each region along with steps may have be taken if experiencing criminal incident. Result reveals features regarding to criminal issues are helpful and easy to be used. However, disadvantage of this research is accessibility to the authorities.
\end{abstract}

Keywords: safety tourism, secure tourism, interaction design, tourism app.

\section{Introduction}

Everyone is expecting to have a vacation with friends or family. However, safety issues is prevented them to visit new tourism place. In development countries, there are many stub tourism place where located in rural areas. It is important to pay attention on safety issues. Tourism industry will going increased inline with safety issues in each location. In last two decades, safety is becoming large issue and impacts on tourism activities and it's sustainability [1]. Feeling unsafe can be caused by various factors, such as local conflict, criminality, natural disasters, and bad social behavior. Safety is becoming a priority factor that determines decision to carry out tourism activities. It is an opportunity and added value for tourism place. As UNWTO stated in 2004, tourism destinations in developing countries can provide alternative trips, however safety guarantee must be provided while traveling [2]. The role of applications plays a key role in accelerating tourism sector rather than just as digitalization tool. Those acceleration process has an impact in transforming other sectors such as social and economic [3].

Smartphone user in Indonesia reaches 60 million in 2017 and it be predicted to surpass 89 million in 2022 [4]. The advantage of using smartphone is its accessibility. As a gadget, smartphone is easy to bring and operated in any condition while traveling. So, it is relevant to design apps based on mobile device. Safety concept that provided in this research aims to shift technology paradigm forward. Technology is evolving and changing rapidly. Technological 
paradigm must be changed from a marketing-driven tool to a knowledge creation tool. Within knowledge creation tool, in tourism sector, technology is applied as part of strategic plan than just as a supporting tool. This study aims to convert safety concept into apps. First step, we should identify the need of safety in tourism activities that experienced by prospective users. Results of the study can be used as insight in designing tourism apps by prioritizing tourist safety. This concept is represented by interaction design. Interaction Design, abbreviated as $\mathrm{IxD}$, is one of the disciplines in User Experience (UX) that is closely related to HCI (Human Computer Interaction) which study the relationship between users, goals, needs, tasks, experiences and what users want [5].

In the rest of paper, we divide discussion into sections. Following section, provide methodology that is used to design IxD. Third, user research discuss about observation method that is determined to observe user's need. Fourth, result of IxD and discussion is expanded into preventive action/early warning and first aid action when experiencing safety issues. Last, conclusion and future works are provided.

\section{Design Methodology}

This research generally aim to discover two main matter, the concept of safety traveling and its implementation on apps. The concept of safety traveling is strengthened by literature study and technically by observing similar apps. Conversion concept into apps utilizes following steps that require comprehensive discussion on psychological and technical aspects. Next, methodology of the designing apps are discussed. Design of the tourism apps is developed based on the accessibility on safety tourism. In order to ensure apps is designed correctly, ten's design principles of Nielsen are used as guideline. Furthermore, psychological aspect, apps is measured by involving personas (explained in next chapter) utilizing cognitive walkthrough $(\mathrm{CW})$.

Combined method is required to ensure high quality usability is provided. According to ISO 9241-11 published in Bevan \& Carter (2015), usability is the extent of product or service can be used by user to achieve certain goals effectively and efficiently so user becomes satisfied in the context of use [6]. We utilize wireframe and prototype in this study. Wireframe is useful to transform ideas into visual form. This aim to provide effective communication with personas while conducting user research. While prototype is used to test interaction of apps. Nielsen principles aims to ensure design is appropriate, while $\mathrm{CW}$ aims to ensure interaction is intuitive. Intuitive means apps is friendly and has appropriate interaction when operated by user. Nielsen principles applied by following HE method. According to (Nielsen, 1990), Heuristic Evaluation (HE) is a usability evaluation method aims to discover usability problems by examining user-interfaces (UI) based on provided usability principles. Evaluator, in this research is designer itself, measures the usefulness, efficiency, and effectiveness of the UI [7]. Ten's Nielsen principles are visibility of system status, match between system and real world, user control and freedom, consistency and standars, error prevention, recognition rather than recall, flexibility and efficiency of use, aesthetic and minimalist design, help user recognize and diagnose and recover from error, and help and documentation [7]. While Cognitive Walkthrough (CW), according to (Rieman et al, 1995), is a technique that is used to evaluate interaction design $(\mathrm{IxD})$, with particular attention to the interaction in order to support exploratory learning, which is intended for first-time (novice) user without conducted prior formal training. We provide indicators to measure interaction, which are adopted from Shneiderman and Plaisant (2010). There five factors are used. These five factors are determined as indicator when measurement process in CW [8]. 
a. Time to Learn, less incorrect task by personas means apps is easy to be learn by novice user. There are three category of user, they are novice, knowledgeable intermediate, and expert user [8].

b. Speed of Performance, less time is spend by personas to finish a task indicate that apps is efficient.

c. Rate of errors by users, more error conducted by personas for each task indicate that design element is required to be revised.

d. Retention over time, limit time is given for each task based on its complexity.

e. Subjective satisfaction, beside indicators provided, user is subjectively asked to express their opinion in order to improve interaction quality.

\section{User Research}

In order to find problem and provide solution that is discovered from user's need, it is required to discover each personas deeply. In Design Thinking, we mentioned it as emphaty. Emphaty is beginning step of user research where user's need is discovered psysiologically and psychologically. It is required to follow and note their activity. At final step, we visualize it into wireframe. User research is a way to gather data and provide problems [9]. Better IxD requires understanding on discovering process about user-apps interaction [10].

\subsection{User Personas}

User personas (personas) is a documentation that contains information about the enduser's character. Kunci memilih personas adalah ketepatan memilih individu. Sekelompok personas tersebut mewakili kebutuhan dari kelompok besar pengguna [11]. It contains an explanation of user's characteristics related to the goals, interests, and needs related to their expectation on the apps to be developed. In developing $\mathrm{IxD}$, the role of personas is important in testing process and sorting out features which are considered important. According to Personas is an interaction design technique in the terms of: decisions, communication, consensus building, commitment, assessment and contribution to overcome problem of interaction design modeling [11].

Personas template that is used in this study is shown in Figure 1. Profile area contains user's personal data such as age, place of birth, and occupation. Goals/Motivations, description of the objective to be achieved and then summarized in points. Frustrations, description of difficulty for user based on apps to be developed. Initial observation is conducted by interviewing potentially end-users and stakeholders. Interviews were conducted using Semistructured Qualitative Interview technique. Based on information collected, five personas were chosen to represent all needs. Personas were chosen based on the analysis using the calculation of the largest percentage of all respondents. There are five personas who chosen in this study.

All personas have similar background, they are enjoy to traveling. However, they have similar problem, hesistancy to traveling caused by safety factors. Some of factors are criminality, social unrest, violating customary rules, and unpredictable access to locations. By the concept provided, they expect to be able to contact authorities easily. In addition, as a preventive consideration, they are expecting information related to safety issues which is attached to each tourism place.

Based on selected personas in this study, then observations were made based on their psychological and physiological aspects. From psychological aspect, observations are conducted by identifying expectations and difficulties encountered based on the previous 
experiences. From physiological aspect, observations are made by testing directly utilizing provided wireframe. Based on these observations, an overview of Safe Tourism appls is obtained in form of IxD that represent the goals of each personas. Next step is designing prototypes and testing it.

\subsection{Wireframing}

Following figure presents wireframe that is produced from the observation on personas. Purpose of providing wireframe is facilitating continued communication between designer and personas. By utilizing visual medium, concepts offered is clearer to be understood by personas. Consequently, potential misunderstanding is minimized. Both designer and personas can express their desire in concrete.
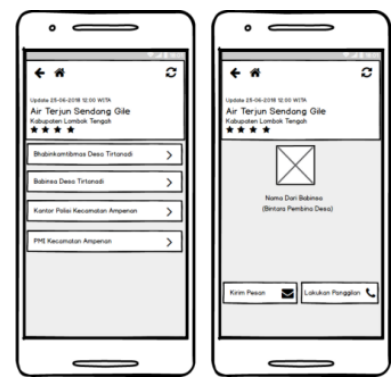
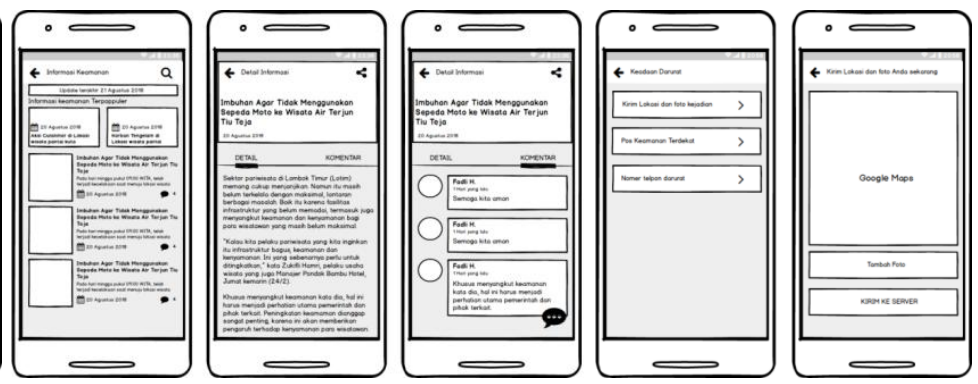

Fig.1. Wireframe produced based on user research.

Results of the discussions with personas are documented and used as a reference for designing prototypes. Prototype will be tested by personas. Testing prototype aims to produce apps that are intuitive and have high usability. Detailed discussions about prototype and testing are discussed in next chapter.

\section{Result and Discussion}

Results of the study, systematically divided into several section. First, presentation of the prototypes present and discuss the matters relating to the provided safety features. Presented prototypes is final result of several iterations that have been carried out. Iteration is conducted by testing to five personas (cognitive walkthrough). Each revision has been revised in following prototypes. In addition, to ensure the interface is accordance with design principles, it is designed by following ten Nielsen's principles. Second step, provide discussion of finding on the topic and potential improvement in further research. Interaction design in this study is still an analysis which generated by user needs. Some aspects, such as implementation in real case and contact accessibility to the authorities (police and hospital departement) have not been discussed further.

Final prototypes which are associated with safety factors are presented. Prototypes have being re-designed iteratively based on feedback in usability testing. Task scenario are used as guidlines for personas to test prototypes. Indicator that are used is the ten principles of Nielsen's design. While formal language used in the Safe Tourism apps is Bahasa Indonesia. 

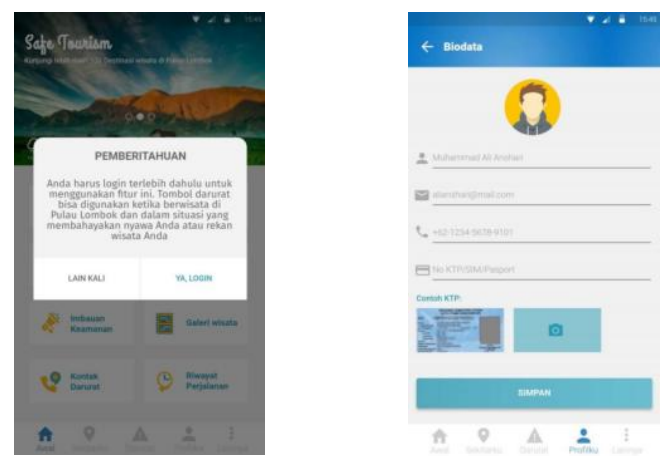

Fig.2. Registration for accessing apps

User are required to fill in their personal into registration form equipped with a valid identification card photo. This is useful to ensure the information can be accounted. As an illustration, when user experienced incident and reports to the authorities, they will be identified based on the information saved. Further discussion will be expanded into two discussion, namely prevention and first aid when experiencing an incident.

\subsection{Preventive Action / Early Warning}

First page of Safe Tourism apps is presented in Figure 3. First step must be passed by the user when successfully registering an account and logging into the system is follow the guidelines how using apps. This is accordance with one of Nielsen's design principles, apps should provide help and documentation.

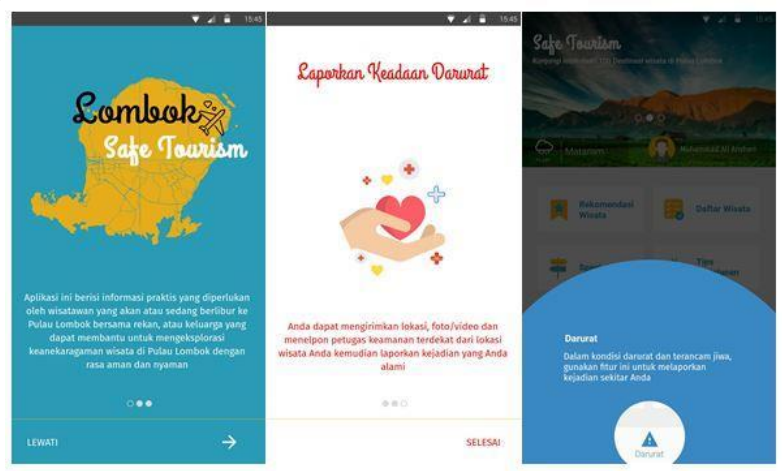

Fig.3. Help and documentation provided in first-time access

Figures above present a guiding land-page that contain the use guidance of apps. Left figure presents a general description of Safe Tourism apps. Furthermore, user can swipe page to the right, so that specific descriptions are displayed associated to safety aspect. This concept is mainstay of designed apps. Swipe to the right presents an emergency call feature when user experiences an incident. Furthermore, Figure 4 presents information/appeals for tourists on certain tourism place. 


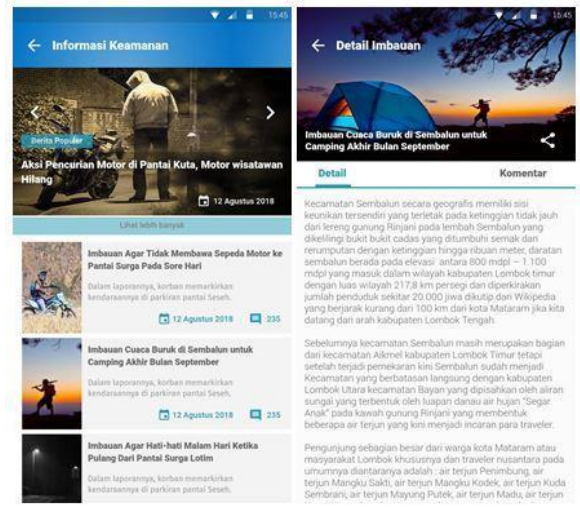

Fig.4. Detail information about safety condition in tourism place

Figure above shows information about current conditions on specific tourism place. Information can change unpredictable depending on the current conditions. Users can post information on comment form or communicate interactively with other users. Testimonial or rating given by fellow user aims to update information on current condition. User testimonial able to present information that is not monitored by the provider (apps).

\subsection{First Aid Action}

Main page of final application is presented on Figure 5. There are two picture in Figure 6 (left and right). Left one is first prototype provided. After measured by personas, button Layanan Darurat (Indonesian spelling for Emergency Services) placement is revised. By placing only on main page, user cannot press the button when exploring other pages of the application. User want to access button easily anywhere and at anytime.

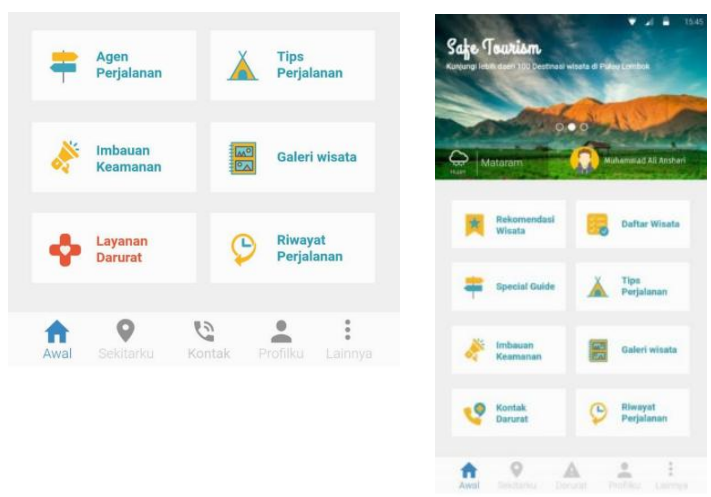

Fig.5. Homepage presentation. 
Layanan Darurat (Emergency Service) is main feature that is provided when user experiencing a safety issues. Layanan Darurat can be accessed by pressing the button. Red is picked up as color, indicates danger and visible lucidly for visual sight. Initial design was placing this button as one of features in homepage. Obstacle is revealed when user is not located in that page or when user is exploring another page. User must return to homepage in order to access the feature. Based on these constraints, Layanan Darurat is moved to fixed menu, located at the bottom. In order to design simple, name is abbreviated to Darurat. Fixed menu will always be displayed as long as user is still on the apps. So, acessibility to access this feature is easy. After Darurat button is pressed, user will be directed to Report page, as shown in Figure 6.

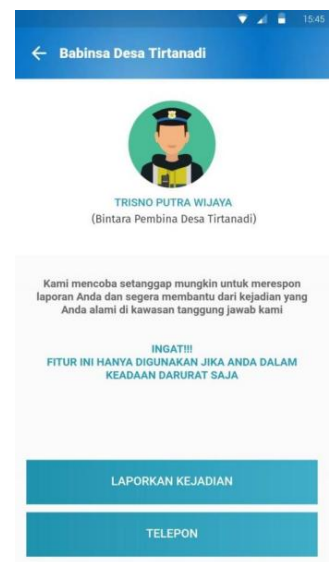

Fig.6. Report page.

Safety information happen in an area cannot be conveyed only by apps provider. Reports from fellow users are important to discover issues. In Figure 6, one feature is presented, namely Report. Users can report occured incidents to Babinsa (the official authority that cover certain area). User can report incident utilize chat feature or phone the number that is provided. In general, application designed includes safety features, both prevention and first aid when user is being threatened. Some of safety features are placed in strategic places and easy to reach in apps. In addition, user's identity is verified after registration form is filled up. To reach users, the authorities will track verified user utilize the GPS feature. Although this still risky to be implemented in areas that have not yet stable internet access. In addition, accessibility to the authorities is still just a concept. Implementation of this concept may require deeper both technical and non-technical aspects.

\section{Conclusion}

Safety feature is recommended to be placed in reachable place. It is important to design interaction of IxD based on safety point of view. During seeking tourism place on apps, safety feature should be easily reachable by user. IxD has designed by following ten principles of Nielsen's UX heuristic. Lombok is chosen as tourism place case study. Two serial measurement has conducted and reveal both qualified usability and meet the design principles. There are three iterations conducted in Cognitive Walkthrough lead to reach qualified usability level. Second, two experts entanglement produce good valuation in design principles. As safety discussion, this IxD provide criminality prevention and criminality helping. 
Features, such as tourism area vurnability level and area description give recommendation to tourist while preparing to go to someplace. Help feature and Call Police are provided aims to give first handling when criminality is happen to them.

\section{References}

[1] I. Kôvári a K. Zimányi, „Safety and Security in the Age of Global,“ Applied Studies in Agribusiness and Commerce, pp. 59-61, 2011.

[2] UNWTO a UNEP, „Making Tourism More Sustainable - A Guide for Policy Makers,“ pp. 11-12, 2004.

[3] Z. Xiang, „From digitization to the age of acceleration: On information technology and tourism,“ Tourism Management Perspectives, zv. 25, pp. 147-150, 2018.

[4] K. Machmud, „The Smartphone Use in Indonesian Schools: The High School Students' Perspective," Journal of Arts \& Humanities, zv. 7, \%1. vyd.3, pp. 33-40, 2018.

[5] J. Preece, H. Sharp a Y. Rogers, Interaction design: beyond human-computer interaction. 4. ed, John Wiley \& Sons, 2015.

[6] N. Bevan a J. Carter, „ISO 9241-11 Revised: What Have We Learnt About Usability Since 1998?,“ rev. International conference, HCI International 2015, Los Angeles, 2015.

[7] J. Nielsen a R. Molich, „Heuristic evaluation of user interfaces,“ rev. SIGCHI conference on Human factors in computing systems, 1990.

[8] B. Shneiderman a C. Plaisant, Designing the user interface: strategies for effective human-computer interaction, Pearson Education India, 2010.

[9] M. Hassenzahl a N. Tractinsky, „User experience - a research agenda,“ Behaviour \& Information Technology, zv. 25, \%1. vyd.2, pp. 91-97, 2006.

[10] E. Goodman, M. Kuniavsky a A. Moed, Observing the User Experience (2nd Edition), Morgan Kaufmann, 2012.

[11] A. Cooper, R. Reimann a D. Cronin, About the Face: The Essentials of Interaction Design, Indianapolis: Wiley Publishing, 2007. 